\title{
Exemplo de estruturação do texto no método de análise histórico-crítica
}

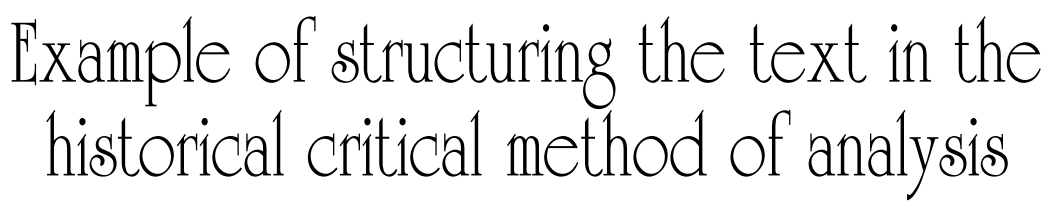

Prof. Dr. Cézar Teixeira* Prof. Me. Antonio Wardison C. Silva**

Resumo: O presente artigo tem o objetivo de apresentar um exemplo de estruturação do texto bíblico no modelo do método de análise histórico-crítico. Para tanto, será apresentada a estrutura de argumentação segundo esse método a partir da análise do contexto de refeição na dinâmica da traição, a qual é exemplificada através do Evangelho de Marcos 14,17-21. Iniciaremos com a apresentação das análises imediatas do texto bíblico em discussão. A seguir, investigaremos as relações no contexto mediato e concluiremos com a reflexão sobre as relações no conjunto do texto de Marcos. Portanto, com este estudo, objetiva-se ressaltar a importância e estrutura própria do método de análise histórico crítico.

Palavras-chave: Método, Estruturação, Refeição, Traição.

Abstract: This paper aims to present an example of the biblical text structuring the model of historical-critical method of analysis. Therefore, the structure of arguments will be presented according to this

\footnotetext{
* Doutor em Teologia Bíblica pela Pontifícia Universidade Santo Tomás de Aquino, Roma. É Professor da Faculdade de Teologia da PUC-SP, no Departamento de Teologia Fundamental. Faz parte do grupo de pesquisa: Verdade, Ética e Educação em Direitos Humanos, pela Universidade Federal de Mato Grosso do Sul-UFMS: http://dgp.cnpq.br/buscaoperacional/ detalhepesq.jsp?pesq=9044623229923577

** Mestre em Filosofia pela Pontifícia Universidade Católica de São Paulo. Graduado em Filosofia e em Teologia. Faz parte do grupo de pesquisa: Verdade, Ética e Educação em Direitos Humanos, pela Universidade Federal de Mato Grosso do Sul - UFMS: http://dgp. cnpq.br/buscaoperacional/detalhepesq.jsp?pesq=9044623229923577
} 
method from the analysis of the context of the dynamics of betrayal meal, which is exemplified through the Gospel of Mark from 14.17 to 21 . We begin with the presentation of the immediate analysis of the biblical text under discussion. Next, investigate the relations in the immediate context and conclude with reflections on relations throughout the text of Mark. Therefore, with this study, we aim to highlight the importance and the very structure of the method of historical and critical analysis.

Keywords: Method, Structuring, Meal, Betrayal.

\section{Introdução}

Toda ciência, no interior de sua investigação e linguagem lógico-especulativa, apropria-se de um método, como meio de orientar e qualificar uma operação científica ao encontro da verdade. Um método representa o modo próprio de uma ciência, ou seja, sua natureza e objeto. É ele que oferece as condições de segurança, coesão e logicidade para uma ciência, assim como apresenta suas regras básicas e específicas.

Ora, a teologia, no seu modo próprio de fazer ciência, no sentido de averiguar os procedimentos lógicos e coerentes de uma argumentação, revelada e racionalmente explorada pelos homens - a partir de uma análise histórico-hermenêutica, à luz da fé - também tem um método próprio. Particularmente, a teologia bíblica, em toda sua especulação literária, exegética, apresenta um método particular, o que confere legitimidade às suas investigações, fundamentalmente ancoradas pela análise da estrutura textual, da linguagem própria (semântica) instalada no interior de uma linguagem.

Neste sentido, o presente texto tem o objetivo de apresentar o modelo de estruturação de um texto pelo método histórico crítico. Para alcançar tal objetivo, este artigo apresentará uma análise sobre a mesa de refeição e sua estreita ligação com a traição, no contexto da relação entre Jesus e Judas. 


\section{Relações imediatas do texto}

A sequência de Mc 14,17-21, ${ }^{1}$ em suas relações internas, pode ser analisada em três partes distintas. A primeira é composta pelos vv. 17-18a; a segunda, vv. 18b-20; e a terceira, v. 21.

$\mathrm{O}$ v. 17 tem a função de introduzir a perícope ${ }^{2}$ e mantém relações com vários versículos da mesma natureza, isto é, versículos como estes possuem elementos repetidos e semelhantes quanto aos autores, verbos de movimento, genitivo absoluto, simples particípio e indicação de tempo ou lugar (Mc 14,17.32.43). ${ }^{3}$ Assim, o v. 17 é todo organizado em função do que segue. As indicações que ele aponta como tempo e

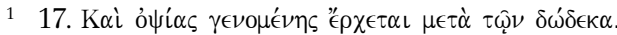

E ao entardecer ele vem com os doze.

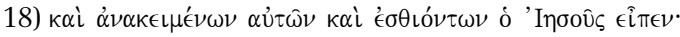

e enquanto eles estavam à mesa e comendo Jesus disse:

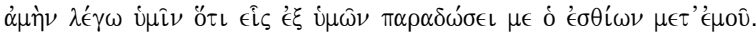

em verdade eu digo vos: um dentre vós me entregará aquele que come comigo.

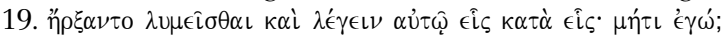

Começaram a ficar tristes e a dizer um cada um: não seria eu, não é?

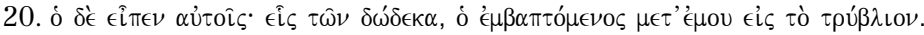

Ele, porém, disse-lhes: um dos doze, aquele que ensopa comigo no prato.

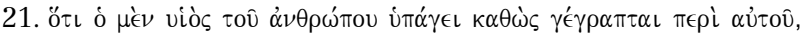

Certo, pois, o Filho do Homem vai conforme está escrito a seu respeito;

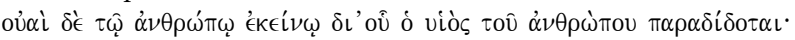

Mas ai desse homem mediante o qual o filho do homem é entregue:

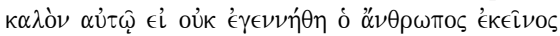

Seria melhor para ele se não tivesse nascido esse homem.

2 L. Schenke, ao analisar o v. 17, define a sua função como: versículo de conexão que serve de dobradiça ou mola, preparando o texto e conectando-o com a perícope anterior (14,12-16) e também como versículo de transição. Cf. Schenke, L. Studien zur Passionsgeschichte des Markus. Tradition und Redaktion in Mkus 14,1-42. Mainz, 1971, p. 198-203.

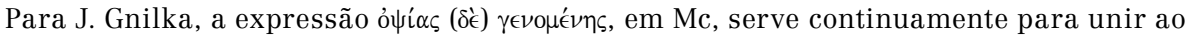
fio da narração como ocorre nas quatro passagens: 4,35; 6,47; 14,17; 15,42. Cf. Gnilka, J. El Evangelio según San Marcos, vol. II. Salamanca, 1986, p. 100. Heil, J. P. Mark 14,1-52: Narratative Structure and Reader-Response. In: Biblical. Roma, 71 (1990) 306, nota 2: "In 14,17 the temporal notice, 'when it was evening', introduces the second scene $(14,17-22)$, of this sandwich".

3 M. Beernaert apresenta uma lista mais vasta de versículos iniciais que se caracterizam por uma semelhança de traços literários repetidos: menção dos atores da cena: vv. 17.32.43; verbos de movimento: vv. 17.26.32.37.43; circunstâncias diversas exprimidas por um genitivo absoluto: vv. 17.18.22.43 ou um simples particípio: vv. 22.23.26.48.50; menções de tempo: vv. 17.43, ou de lugar: vv. 26.32. Cf. Beernaert, M. Structure littéraire et lecture théologique de Marc 14,17-52. Leuven, 1974, p. 242-243. 
atores, são, por um lado, genéricas ou imprecisas e, por outro, desenvolvidas com maior especificidade e ênfase. A indicação de tempo, na

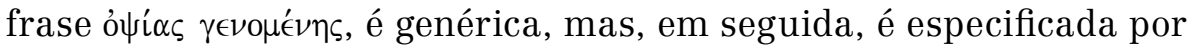

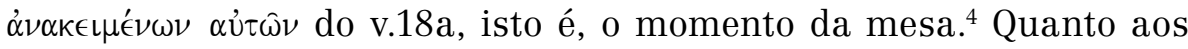
atores da cena, $\delta \omega ́ \delta \epsilon \kappa \alpha$, é o destaque, visto que a referência a Jesus

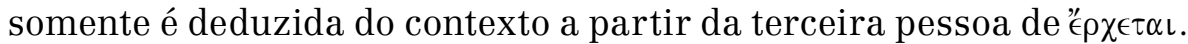

Nesta primeira parte, portanto, a base estrutural do texto apoia-se em dois elementos principais: nos Doze e no momento em que eles estão à mesa de refeição. Ambos os elementos mantém uma relação no conjunto da perícope, isto é, os Doze porque é deles que sairá o traidor e a mesa de refeição porque é o momento privilegiado do anúncio (v. 18b) e do comer com Jesus (v. 18c.20b). ${ }^{5}$

A segunda parte, vv. 18b-20, forma uma estrutura concêntrica do tipo $A B A^{\prime}:{ }^{6}$

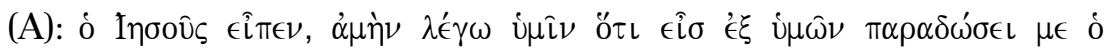

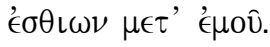

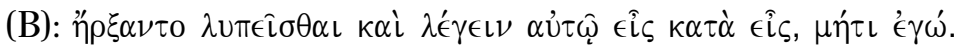

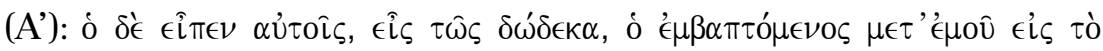

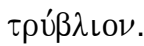

As partes laterais $A$ e $A^{\prime}$ fornecem duas ideias centrais, fundamentadas na refeição e na traição. A refeição, mencionada na primeira parte como refeição de mesa (v. 18a), recebe três características importantes: a) ela foi ampliada ${ }^{7}$ por meio de ó '́ $\sigma \theta^{\prime} \omega \nu$ v. 18c. e por ó

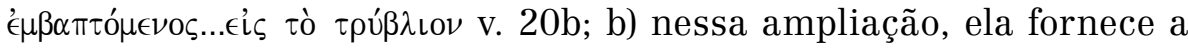
comensalidade do traidor e o comer com Jesus v. 18b.20b: $\mu \in \tau^{\prime} ' \epsilon \mu o \hat{;}$; c)

\footnotetext{
4 Cf. Schenke, L. Studien zur Passionsgeschichte des Markus, p. 204. Em relação a outras indicações, por exemplo Mc 1,32, conferir: Taylor, V. Evangelio según San Marcos. Madrid, 1979, p. 198.

5 Cf. Robbins, “Last Meal”. In: KELBER, W. H. (ed.). The Passion in Mark. Studies on Mark 14-16. Philadelphia, 1976, p. 30. Cf. White, J. L. Beware of Leavened Bread. Markan Imagery in the Last Supper. In: Forum, n. 3 (1987) 58, nota 23.

6 Cf. Dormeyer, D. Die Passion Jesu als Verhaltensmodell. Literatische und Theologische Analyse der Traditions - und Redaktionsgeschichte der Markus-passion. Munster, 1974, p. 99. Robbins, V. K. “Last Meal”, p. 31. Sobre quiasmos conferir: Scott, M. P. Chiastic Structure: A Key to the Interpretation of Mark's Gospel. In: Biblical Teology Bulletin. Bonaventure/ NY, 15 (1985) 17-26; Stock, A. Hinge Transitions in Mark’s Gospel. In: Biblical Theology Bulletin. Bonaventure/NY, 15 (1985) 27-31.

7 Cf. Gnilka, J. El Evangelio según San Marcos. Vol. II, p. 275.
} 
a relação, portanto, entre Jesus e o traidor está enfatizada por meio do comer ou da refeição.

Pela ideia da traição, desenvolve-se a forte tendência em apontar o traidor em três aspectos: a) a força do anúncio enfático, na sentença

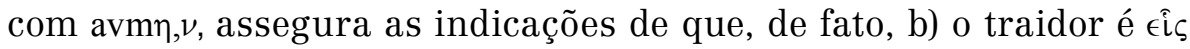

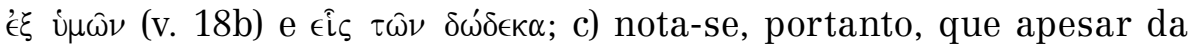
forte tendência em apontar o traidor, em nenhum momento ele vem mencionado pelo nome. O interesse não está em sua identificação, mas na sua pertença como membro da comunidade de mesa de refeição.

A parte central B focaliza três atitudes dos discípulos frente à

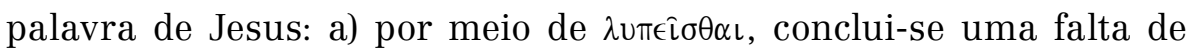
senso ou reflexão diante da declaração de Jesus; b) a expressão $\epsilon \hat{i} \varsigma$

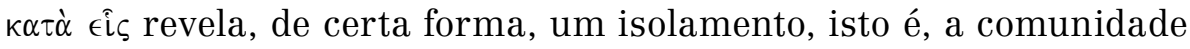
não reage em conjunto para apontar quem é o verdadeiro traidor, mas cada um toma para si a própria declaração; c) a terceira atitude

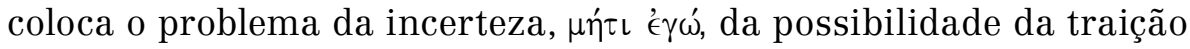
por um comensal. ${ }^{8}$

As atitudes dos discípulos no centro do quiasmo enfatizam a relação entre o modo de ser de Jesus, ao contrário dos próprios discípulos, já que Ele está consciente da sua traição, a ponto de afirmar que o traidor come com Ele e sobre esse fato Ele está seguro. Tudo isto preenche o vazio que se irrompe pela ausência de senso, de participação e certeza dos discípulos diante da comunidade de refeição, abalada pela participação de um membro traidor. A ênfase, portanto, não se coloca apenas na possibilidade da traição por um participante do discipulado, mas também no comer com Jesus que conta com a violação desses sagrados laços pela traição, considerando que tanto

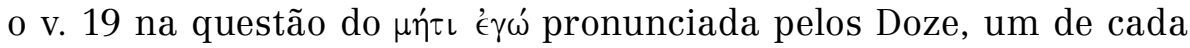

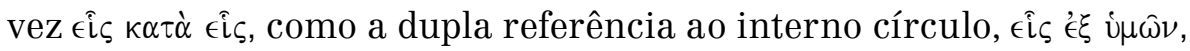
v. 18, e $\epsilon \hat{i} \varsigma \tau \hat{\omega} \nu \delta \omega ́ \delta \epsilon \kappa \alpha, v .20$, nada mais é do que um aumento da frase

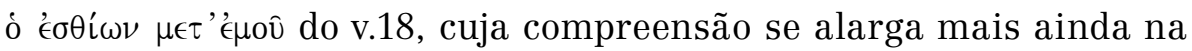
alusão do Sl 41,10, provocando o chamado efeito aumentado. ${ }^{9}$

\footnotetext{
8 Robbins, V. K. “Last Meal”, p. 31.

9 Outros exemplos de efeito aumentado no Evangelho de Marcos conferir: Danker, F. W. The Literary Unity of Mark 14,1-25. In: Journal of Biblical Literature. Atlanta, 85 [1966] 470 e nota 12.
} 
A terceira parte, composta pelo v. 21, possui uma modificada estrutura de oráculo de maldição que o autor constrói como cena conclusiva. Sabe-se que a estrutura de um oráculo possui três partes sucessivas: ${ }^{10}$ a) a introdução, que contém a maldição e revela 0 receptor do julgamento divino; b) o centro, que esclarece o motivo de tal transgressão; c) o final, a sentença da parte de Deus. Na estrutura atual do texto, a primeira modificação situa-se na parte introdutória do oráculo. Aí Marcos acrescenta a ida do Filho do homem em conformidade com as Escrituras (v. 21a). Com isso, a atual conjuntura do oráculo possui agora dois temas: o primeiro, em torno de Jesus identificado como o Filho do homem que cumpre a vontade de Deus e o segundo em torno do traidor, esse homem, que constitui o verdadeiro tema do oráculo, pois a ele são aplicados o oủai (v. 21b) e o julgamento divino (v. 21c). ${ }^{11} \mathrm{O}$ acréscimo de Marcos tem a finalidade ligar, de forma interpretativa, o conteúdo da parte anterior (vv.12b-20) à dimensão do cumprimento das Escrituras. Ora, assim como na segunda parte, o traidor de Jesus é identificado como um companheiro de mesa, sobretudo na linha do Sl 41,10: Até meu bondoso amigo em quem eu confiava que comia do meu pão levantou seu calcanhar contra mim; também na terceira parte (v. 21a) isto se confirma que, de fato, por estas coisas Ele tem que passar porque é vontade de Deus. ${ }^{12}$

$\mathrm{Na}$ segunda parte do oráculo, a causa da ofensa propriamente dita não pode ser identificada pelo verbo paradı,domı, uma vez que este, no passivo teológico, tem como sujeito Deus, pois é Ele quem entrega o Filho do homem. Somente do contexto deduz-se que a traição é o verdadeiro motivo. ${ }^{13} \mathrm{~A}$ ausência deste motivo faz o acento recair na pessoa do traidor, esse homem que, por meio do paralelo antitético entre os v. 21c e b, se contrapõem ao Filho do homem. Por um lado,

\footnotetext{
${ }^{10}$ Robbins, V. K. “Last Meal”, p. 32. Cf. White, J. L. Beware of Leavened Bread, p. 60. ${ }^{11}$ Cf. Robbins, V. K. "Last Meal”, p. 32-33. Cf. White, J. L. Beware of Leavened Bread, p. 60-61.

${ }^{12}$ White, J. L. Beware of Leavened Bread, p. 58: “The statement in Mark 14:21a specifies that it is the Son of Man who is betrayed. It has very close parallels in Matt 26:24a and in Luke 22.22. There is no parallel in John's account of the supper".

${ }^{13}$ Cf. Robbins, V. K. "Last Meal”, p. 33.
} 


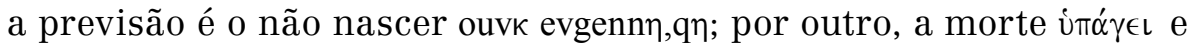
a dor oủai.

\section{Relações no contexto mediato}

Estas relações serão focalizadas pela característica e pela função da narrativa. Os elementos principais são aqui destacados a partir do lugar, do tempo, dos personagens e das ações. Estes possibilitam a relação entre as perícopes limites e também situam o evento da ceia pascal que forma a moldura pela qual perpassa a inteira sequência de Mc 14,12-25.

O lugar - cidade, casa, sala, mesa - e o tempo - o primeiro dia dos Ázimos, ao entardecer, enquanto estavam à mesa - são mencionados progressivamente e vão sofrendo mudanças significativas. Por meio da narrativa, Jesus e os Doze são conduzidos e colocados na mesa de refeição, onde eles se detêm até a saída para o Monte das Oliveiras, no v. 26. Nesse intervalo não há mudança de lugar, uma só é a mesa, uma só é a refeição. ${ }^{14}$

Os personagens dinamizam o evento com atitudes praticadas principalmente por Jesus e os discípulos. Há, porém, uma pequena e relevante mudança. Em 12-16, o autor menciona os discípulos denominando-os por $\mu \alpha \theta \eta \tau \alpha i(\omega \nu)$, enquanto nos vv. 17-21 eles são conceituados pela denominação $\delta \omega \dot{\delta} \epsilon \kappa \alpha$, o estreito grupo de Jesus. Tal conceito é acentuado mais ainda pela menção $\epsilon \hat{i} \varsigma \tau \omega \hat{\omega} \nu \delta \omega \delta \delta \epsilon \kappa \alpha, o$ traidor de Jesus que pratica a ação má, como protótipo do anti-herói. ${ }^{15}$ Para Kelber, a função dos personagens é dupla: a) interna, enquanto participam da trama, antecipando-a e conduzindo-a para a resolução; b) externa, enquanto simbolizam realidades que se unem com os presentes leitores e servem como modelos de significação e conduta. Dentre outros, o autor destaca Judas, os Doze e Jesus: Judas é constantemente introduzido na seção da paixão $(14,10.20 .43)$ e identificado como um dos Doze que compartilha mesa de companheirismo com

\footnotetext{
${ }^{14}$ Robbins, V. K. "Last Meal”, p. 29. Cf. Hein, K. Judas Iscariot: Key to the Last-Supper Narratives. In: New Testament Studies. Cambridge, 17 [1971] 227-232.

${ }^{15}$ Marin, L. Sémiotique de la Passion. Paris, 1971, p. 158.
} 
Jesus (14,18-20). A figura de Judas choca o leitor dentro da realização que surge inimizade de dentro do grupo; como Jesus foi entregue por um dos seus, assim são os cristãos igualmente entregues por um dos seus $(13,12)$. Mas o verdadeiro termo usado para descrever o ato de traição, paradı,domı $(14,10.11 .18 .21 .42 .44)$, integra a traição dentro de um propositado esquema da paixão. Judas, ainda que culpável e amaldiçoado por Jesus $(14,21)$, funciona para traduzir as predições de Jesus $(9,31 ; 10,33 ; 14,41.42)$ dentro da ação. Os Doze, como também os três e Pedro, realizam a função de modelos negativos de discipulado. Eles preparam a ceia pascal, mas parecem não preparados para a exposição de Jesus do inimigo dentro de sua última ceia $(14,19)$. Jesus é o personagem principal do Evangelho e um modelo trabalhoso de definir e difícil de seguir. Ele tem caráter de autoridade e em possessão de detalhado pré-conhecimento de tudo o que está acontecendo. Ele antecipa a precisa posição de sua última ceia (14,13-16), a global difusão do Evangelho (14,9), a dispersão dos discípulos $(14,27)$, a traição de Judas $(14,20)$, a negação de Pedro $(14,30)$ e sua própria morte (14,8.21-24.27.41). Existe uma aura de autoridade em torno de Jesus que estabelece o controle sobre os eventos da paixão. Por outro lado, Ele é golpeado e cuspido, sentenciado para morrer, humilhado e rejeitado por seus seguidores. ${ }^{16}$

As ações destes em 12-16 voltam-se para os preparativos da ceia, na qual Jesus quer comer com seus discípulos, em 17-21 e na seção seguinte eles realizam tal ação com diversas características. No início, Jesus é o Mestre que prepara de modo extraordinário o banquete pascal para comer com seus discípulos. Em 17-21, porém, Ele torna-se o amigo e companheiro, formando a comunidade de mesa, comendo até com o traidor. Na cena seguinte, contudo, Ele se doa aos seus por meio de palavras e sinais. ${ }^{17}$

No anúncio da traição, Marcos chama a atenção dos leitores para as ações dos personagens de maneira dramática, contrastante e

\footnotetext{
${ }^{16}$ Cf. Kelber, W. H. (ed.). The Passion in Mark. Studies on Mark 14-16. Filadelphia, 1976, p. $172-176$.

${ }^{17}$ Schlier, H. Il Mistero Pasquale e la Passione secondo Marco. 2. ed. Milano, 1991, p. 80.
} 
repetida. ${ }^{18}$ A traição, fato singular na inteira sequência, interrompe a harmonia produzida pelo clima de festa pascal que vem predominando desde o v. 12 ao v. 18a, retornando somente no vv. 22-25. Agora, a comida associada à traição, faz os atuantes externarem sentimentos.

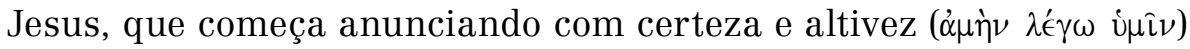
sobre o amigo que o trai, termina lamentando com pesar (ov̉à $\delta \dot{\epsilon} \tau \hat{\omega}$ $\left.\dot{\alpha} \nu \theta \rho \omega \dot{\pi} \omega \mathfrak{\epsilon}^{\prime} \kappa \in \dot{L} \nu \omega\right)$. A ênfase não está mais colocada sobre o desejo do Mestre nem ainda nos seus sinais, mas na manifestação do seu destino de morte aos Doze, os quais devem refletir. ${ }^{19}$

A função própria do anúncio não está em narrar os fatos como realmente aconteceram. A prova disto é que se esperava, mesmo com os indícios evolutivos, um desenvolvimento mais detalhado da ceia, como também na ordem atual do Evangelho o leitor já sabe que as palavras do anúncio de Jesus sobre a traição aconteceram de forma definitiva (Mc 3,19). Apesar da forte tendência para indicar a pessoa do traidor, nem mesmo isto evolui. ${ }^{20}$

A narrativa, com seus recursos linguísticos gramaticais e sua forma de profecia, incide sobre o contraste produzido pela justaposição das ações refeição/traição, que por sua vez são a causa da

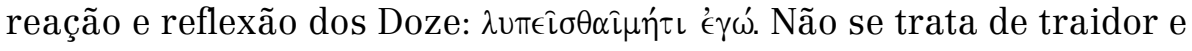
traído, mas de um que come com Jesus. ${ }^{21}$ Com isto, a narrativa dá a estas ações uma força maior que resulta em um salto de qualidade, tornando-as, mais do que simples eventos narrados, instrumentos de instrução e interiorização. ${ }^{22}$ Logo, a traição não é de qualquer um, mas de um discípulo companheiro e a refeição é especial, ou seja, da ceia pascal e de mesa, que constitui a comensalidade. ${ }^{23}$ Comer com Jesus implica nesta comensalidade conflitiva que os Doze devem assumir como conduta no processo de interiorização da paixão de Jesus.

\footnotetext{
${ }^{18}$ Heil, J. P. Mark 14,1-52: Narrative Structure and Reader-Response. In: Biblical. Roma, 71 (1990) 305-331.

${ }^{19}$ Stock, P. K. Il Racconto della Passione nei Vangeli Sinottici I, 3. ed. Roma: PIB, 1992, p. 67.

${ }^{20}$ Gnilka, J. El Evangelio según San Marcos. Vol. II, p. 277.

${ }^{21}$ Derrett, J. D. M. The Upper Room and the Dish. Heytrop Journal, 26 (1985) 375.

${ }^{22}$ Stock, P. K. Il Racconto della Passione nei Vangeli Sinottici I, p. 67.

${ }^{23}$ Léon-Dufour, X. O Partir do Pão Eucarístico segundo o Novo Testamento. São Paulo: Vozes, 1984, p. 64.
} 
Todos sofrem por causa dessa comensalidade brutalmente violada, porém, pelo próprio caráter profético do anúncio, Jesus, ao contrário dos Doze, está consciente do destino que lhe compete e para isto quer alertar os seus discípulos. ${ }^{24}$

\section{Relações no conjunto de Marcos}

A perícope no macro texto mantém uma estreita relação com o tema das histórias de alimentação em Mc 6,30-44; 8,1-10. O drama, altamente conflitivo, manifesta-se, sobretudo na prática de Jesus ao comer com publicanos e pecadores. Prática essa radicalmente excluída pelos fariseus. $O$ anúncio da traição, portanto, continua o filão narrativo sobre as diversas refeições vinculadas ao sofrimento, à morte e à ressurreição que termina na Eucaristia. Robbins defende a tese de que esta comida final completa o drama das histórias de alimentação em Mc 6,30-44 e 8,1-10, que têm como finalidade defender uma visão de que os poderes milagrosos de Jesus são as bases para a crença e para vincular a comida cristã ao sofrimento de Jesus, morte e ressurreição em desenvolvimento. ${ }^{25}$

Por outro lado, o tema do companheirismo de refeição de mesa é uma exaltação predeterminada do sucesso de Jesus, que ultrapassa a esfera da traição, com sua conotação de desgraça. O tema encontra necessariamente sua relação com o AT, sobretudo na citação do Sl 40,10

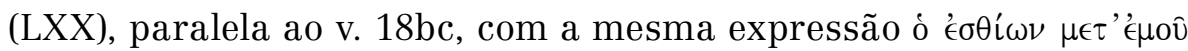

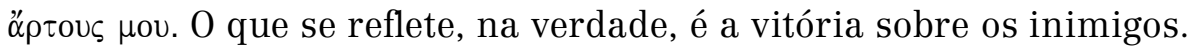
Jesus partilhando a refeição com seus discípulos, portanto, contrapõe-se como sinal de vitória à ação abominável dos seus inimigos que penetram no círculo mais estreito de sua vida, por meio do traidor. ${ }^{26}$

Outra estreita relação que o anúncio da traição mantém é com os anteriores anúncios de paixão, morte e ressurreição (Mc 8,31;

\footnotetext{
${ }^{24}$ Cf. Beernaert, M. Structure littéraire et lecture théologique de Marc 14,17-52, p. 250-251. Cf. Schelkle, K. H. Teologia do Novo Testamento I. São Paulo, 1977, p. 58.

${ }^{25}$ Cf. Robbins, V. K. "Last Meal”, p. 21. Cf. Harrington, W. Mark. Dublin, 1979, p. 218. Cf. Léon-Dufour, X. O Partir do pão Eucarístico segundo o Novo Testamento, p. 212.

${ }^{26}$ Cf. Danker, F. W. The Literty Unity of Mark 14,1-25. In: Journal of Biblical Literature. Atlanta, 85 (1966) 471-472.
} 
$9,12.31 ; 10,33.39 .45 ; 12,6.10)$. Todos eles juntos têm os mesmos fatores em comum, isto é, a instrução e preparação de Jesus aos discípulos sobre sua sorte. A novidade do anúncio da traição está na conduta dos discípulos, em sua primeira instrução para que também eles assumam a mesma conduta de Jesus que conta com um destino de paixão, morte e ressurreição. ${ }^{27}$ A reação de tristeza e interrogação dos discípulos, frente à notícia da traição por um companheiro de mesa (v. 19), revela a ausência de tal conduta e o pouco conhecimento a respeito de Jesus e do seu caminho. ${ }^{28}$ Esse mesmo fio narrativo sobre a conduta dos discípulos é retomado pelos anúncios negativos, nos quais a perícope forma uma tríade (traição, escândalo e negação) que aprofunda os elementos instrutivos para tal conduta e preserva os seus de tais perigos, para os quais Jesus é consciente e os aceita livremente em conformidade com a vontade de Deus. ${ }^{29}$

No sofrimento de Jesus, está implícito o tema da paixão dos justos que, no anúncio da traição, se destaca de maneira decisiva, conforme a função penosa e forte que exerce a perícope. A paixão dos justos reúne outros temas, sobretudo os que estão explicitamente narrados no texto como: 1 - O Filho do homem: a) o destino doloroso do Filho do homem: Dn 7,21; b) a morte do Filho do homem segundo as Escrituras: Sl 41; 55,13; c) o sofrimento do Filho do homem: Sl 41,10. 2 - Traidor:

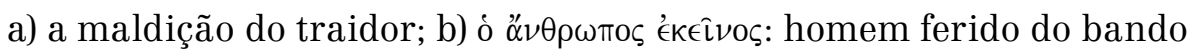

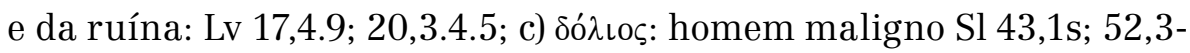
6; 109,2-5; Sl 109,8; At 1,20; Sl 31,19. 3 - Traição: a) trair recorda 0 Servo de Deus: Is 53,6.12 e entra na fé cristã como o que foi entregue: Rm 4,25; b) traição pela comunhão $;^{30}$ c) traição de Davi: 2Sm 15-17; Sl 55, 13-15; Is 1,5. 4 - lamentação e ameaça: a) ouvaí: anúncio de morte

${ }^{27}$ Cf. Stock, P. K. Il Racconto della Passione nei Vangeli Sinottici I, p. 67-68.

${ }_{28}$ Para L. Schenke, os discípulos confrontam no Evangelho de Marcos a tristeza afirmada com a paixão de Jesus e a tudo o que se relaciona com uma profunda falta de discernimento (cf. 8,31ss; 9,10.32; 10,32; 14,29.32ss.50.66ss). Com isto, é misterioso para eles também o anúncio da traição. Torna-se claro com $\lambda u \pi \epsilon i \sigma \theta \alpha \iota$ que os discípulos conheceram pouco Jesus e seu caminho. Cf. Schenke, L. Studien zur Passionsgeschichte des Markus, p. 227. ${ }^{29}$ Cf. Brown, R. E. The Death of the Messiah I. New York- London, 1994, p. 139-141. Cf. a função das tríades na composição do Evangelho de Marcos em Neirynck, F. L’Évangile de Marc (II). In: Ephemerides Theologicae Lovanienses, 60 (1979) 27-42.

${ }^{30}$ 1QH 5,25: escritos de Qumrã. 
e proclamação do juízo; b) a lamentação é um grito da reprovação escatológica dos profetas; c) a qualidade de oủaí é ilustrada pela ame-

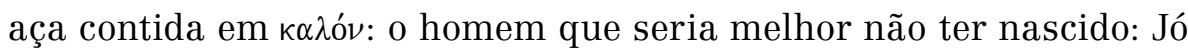
3,3s; Ecl 23,1.

\section{Conclusão}

O texto possui uma estrutura tripartida de caráter introdutório, concêntrico e oracular. Nessa estrutura, o curso dos acontecimentos transcorre-se entre Jesus e os Doze que constituem uma comunidade de mesa. Esta se defronta com o problema da traição por um de seus membros em circunstância relacional, isto é, o traidor mantém uma estreita relação com Jesus. Frente a este problema, a comunidade está desarticulada para o enfrentamento. A partir daí projeta-se um futuro de morte e de ruína.

O contexto mediato situa a cena com maior precisão, na qual o leitor percebe as mudanças significativas. A mesa é o espaço social que reúne Jesus e seus discípulos para comer a Páscoa, mas é, sobretudo, com seu estreito grupo dos Doze, que Jesus realiza tal acontecimento preparando-se para a separação definitiva (v. 25). Antes, porém, dessa realidade transcendente, a comunidade de mesa perpassa pelo imanente contraste entre a união e a separação de Jesus configurado pela traição/refeição. Nessa realidade imanente, onde se dá a comensalidade conflitiva, Jesus é o amigo e companheiro que come com seu próprio traidor. A função da perícope, em meio a este conteúdo, é intensificá-lo e obter um efeito impetuoso gerando consciência que vai além da própria fonte nascente, traição/refeição. A estrutura, portanto, evidencia a intrínseca relação com o contexto mediato.

Por último, percebe-se que a estrutura do texto está relacionada não somente com os acontecimentos imediatos, mas também a fatos anteriores no início do Evangelho. São as histórias sobre refeições, incluindo mesa de refeições. Estas, quase sempre, possuem conotações conflitivas, o que significa uma relação profunda com o todo do Evangelho de Marcos, visto que a alimentação relaciona-se ao sofrimento, à morte e à ressurreição de Jesus. As relações também são estabelecidas com temas, cujas bases repousam no AT, iluminando-os 
e dando-lhes profundidade. É no profundo destes conhecimentos que a própria cadeia de conflito refeição/traição, motivando uma espécie de eterna prisão, encontra nestas e noutras reflexões sua própria superação, sobretudo no âmbito da mesa de refeição.

\section{Bibliografia}

BEERNAERT, M. Structure littéraire et lecture théologique de Marc 14,1752. Leuven, 1974. (Biblioteca Ephemerides Theologicae Lovanienses 34). BROWN, R. E. The Death of the Messiah, vol. I-II. New York-London, 1994. (A Commentary on the Passion Narratives in the Four Gospels).

DANKER, F. W. The Literty Unity of Mark 14,1-25. In: Journal of Biblical Literature. Atlanta, 85 (1966) 467-472.

DERRETT, J. D. M. The Upper Room and the Dish. In: Heytrop Journal, 26 (1985) 373-381.

DORMEYER, D. Die Passion Jesu als Verhaltensmodell. Literatische und Theologische Anályse der Traditions - und Redaktonsgeschichte der Markus-passion. Munster, 1979.

GNILKA, J. El Evangelio según San Marcos, vol. I-II. Salamanca, 1986. (Biblioteca de Estudios Bíblicos 55/6).

HARRINGTON, W. Mark. Dublin, 1979. (New Testament Message 4, a Biblical-Theollogical Commentary).

HEIL, J. P. Mark 14,1-52. Narratative Structure and Reader-Response. In: Biblical. Roma, 71 (1990) 305-331.

HEIN, K. Judas Iscariot: Key to the Last-Supper Narratives. In: New Testament Studies. Cambridge, 17 [1971] 227-232.

KELBER, W. H. (ed.). The Passion in Mark. Studies on Mark 14-16. Filadelphia, 1976.

LÉON-DUFOUR, X. O Partir do Pão Eucarístico segundo o Novo Testamento. São Paulo: Loyola, 1984.

NEIRYNCK, F. L’Évangile de Marc (II). In: Ephemerides Theologicae Lovanienses, 60 (1979) 01-42. (A propos de R. Pesch, das Markus-evangelium, 2. Teil).

ROBBINS, “Last Meal”. In: KELBER, W. H. (ed.). The Passion in Mark. Studies on Mark 14-16. Philadelphia, 1976.

SCHELKLE, K. H. Teologia do Novo Testamento I. São Paulo: Loyola, 1977. 
SCHENKE, L. Studien zur Passionsgeschichte des Markus. Tradition und Redaktion in Mkus 14,1-42. Mainz, 1971. (Forschung zur Bibel).

SCHLIER, H. Il Mistero Pasquale e la Passione secondo Marco. 2. ed. Milano, 1991.

SCOTT, M. P. Chiastic Structure: A Key to the Interpretation of Mark's Gospel. In: Biblical Teology Bulletin. Bonaventure, 15 (1985) 17-26.

STOCK, A. Hinge Transitions in Mark’s Gospel. In: Biblical Theology Bulletin. Bonaventure/NY, 15 (1985) 27-31.

STOCK, P. K. Il Racconto della Passione nei Vangeli Sinottici, vol. I. 3. ed. Roma: PIB, 1992. (3. ristampa ad uso degli studenti).

TAYLOR, V. Evangelio según San Marcos. Madrid, 1979.

WHITE, J. L. Beware of Leavened Bread. Markan Imagery in the Last Supper. In: Forum, n. 3 (1987) 49-63. 